\title{
COLOMBIA: UN PANORAMA MENOS CONFUSO
}

\author{
Colombia: A clearer scenery
}

\author{
MARGARITA BATLLE \\ Universidad Externado de Colombia
}

\section{GUSTAVO DUNCAN}

Universidad de los Andes y Profesor invitado Universidad EAFIT

\begin{abstract}
RESUMEN
Al alcanzar la mitad del periodo de gobierno del presidente Juan Manuel Santos (2010-2014), este artículo se centra en un proceso de reconfiguración de las fuerzas políticas en Colombia que comenzó en 2010 cuando este llegó a la Presidencia y se selló en 2012, con la ruptura definitiva con el ex-presidente Uribe, partiendo de la idea de que luego de un periodo de confusión y volatilidad política, se llegó finalmente a un panorama en que los adversarios y sus soportes sociales pueden distinguirse con un mínimo de claridad. Se analizan los cambios y las rupturas que se han dado durante esta administración en términos de agenda política y económica, especialmente respecto de temas como los cambios del sistema de partidos, la relación de Santos con el Congreso, las negociaciones con las FARC en el marco del comienzo del proceso de paz y el crecimiento económico asociado con la minería.
\end{abstract}

Palabras clave: Juan Manuel Santos, reconfiguración de las fuerzas políticas, Congreso, proceso de paz, minería.

\begin{abstract}
As we reach the first half of President Juan Manuel Santos' term (2010-2014), this article focuses on the process of reconfiguration of political forces that started in Colombia when he became President in 2010, and which came to fruition in 2012, with the definitive breakup with former President Uribe. We build on the idea that, after a period of confusion and political volatility, the country finally reached a situation where the adversaries as well as their social support can be distinguished more accurately. We analyze changes and ruptures occurred during this administration in terms of political and economic agenda, especially on issues such as changes in the party system, Santos' relationship with Congress, the negotiations with FARC in the beginning of the peace process and economic growth associated with mining.
\end{abstract}

Key words: Juan Manuel Santos, Reconfiguration of Political Forces, Congress, Peace Process, Mining. 


\section{INTRODUCCIÓN}

El 2012 fue para Colombia un año en que muchas encrucijadas de la vida política finalmente comenzaron a aclararse. No en el sentido del logro de una paz duradera ni de un final del permanente estado de polarización, sino de reposicionamiento de las fuerzas políticas en juego. Hace un par de años los elementos básicos para un análisis de coyuntura no eran claros. Álvaro Uribe, luego del rechazo de la Corte Constitucional a su segunda reelección, había respaldado en las elecciones presidenciales de 2010 a su antiguo ministro de defensa Juan Manuel Santos. Sin embargo, cuando todo daba para pensar que sería un gobierno de continuidad con las diferencias naturales de los matices de cada gobernante, la agenda reformista planteada por Santos y las crecientes críticas de Uribe dieron pie a una serie de enfrentamientos que no dejaban claro si el partido al mando del ejecutivo era de gobierno o de oposición.

Por último, dos acontecimientos sellaron la suerte de la relación. A principios de 2012 el rumor de diálogos de paz con las FARC, por un lado, llevó a Uribe a declararse en abierta oposición. Y por otro lado, en vez de mantener la distancia que tradicionalmente mantenían los expresidentes en el ejercicio de la política menuda Uribe ha decidido liderar la organización de un nuevo partido, el Puro Centro Democrático -con posterioridad Centro Democrático (CD)-, para arrebatar las mayorías en el legislativo del gobierno y para postular un candidato que compita contra Santos en una eventual campaña por la reelección presidencial.

A la luz de este panorama y al alcanzar la mitad del periodo de gobierno de Santos, la siguiente revisión de coyuntura se centra en un proceso de reconfiguración de las fuerzas políticas en Colombia que comenzó en 2010 cuando este llegó a la Presidencia y se selló en 2012 con la ruptura definitiva con Uribe, partiendo de la idea de que luego de un periodo de confusión y volatilidad en la política se llegó finalmente a un panorama en que los adversarios y sus soportes sociales pueden distinguirse con un mínimo de claridad. El objetivo se centra en analizar los cambios y las rupturas que se han dado durante esta administración en términos de agenda política y económica.

La primera sección del artículo se centra en los cambios que ha experimentado el sistema de partidos colombiano, teniendo en cuenta tanto la crisis interna del Partido Social de Unidad Nacional (PU) y la permanencia de la izquierda por tres periodos en la alcaldía de la capital del país, así como la convivencia de los partidos tradicionales con novedosas formas de organización para la competencia electoral como los son los movimientos ciudadanos y las candidaturas por firmas, todo lo anterior en el marco de un gobierno que ha apostado a la formación de una gran coalición de apoyo.

El segundo apartado hace un balance de la primera mitad de la administración de Santos, centrándose, primero, en su relación con el Congreso y algunas cuestiones clave de su política exterior; segundo, en las negociaciones para la terminación del conflicto armado entre el gobierno y la guerrilla de las FARC; y tercero, en el crecimiento económico en el marco de lo que se ha denominado desde el mismo gobierno como "la locomotora minera". Para finalizar, se elaboran unas conclusiones en las que se reflexiona sobre 
el futuro inmediato y, especialmente, sobre las estrategias que políticos y partidos desplegarán en la lucha por acceder al poder en las elecciones nacionales de 2014.

\section{UN SISTEMA DE PARTIDOS QUE SE REACOMODA}

\section{De la U de Uribe a la U de Santos}

La llegada de Álvaro Uribe a la Presidencia en 2002 puso en evidencia un fenómeno que venía gestándose desde la promulgación de la constitución de 1991: los partidos tradicionales y sus respectivos caudillos ya no controlaban el poder de forma exclusiva, sino que las nuevas organizaciones, llámense partidos o movimientos ciudadanos, con líderes nuevos o reciclados, tienen un espacio asegurado en la lucha por el poder político en el país. En el marco de los nuevos espacios copados por los partidos no tradicionales, Juan Manuel Santos fue elegido por el PU, declaradamente "uribista", pero al llegar al Palacio de Nariño se distanció de los postulados del ex-presidente (Wills-Otero y Benito, 2011) y llamó a formar una gran coalición de gobierno, la que se denominó Unidad Nacional. En esta coalición tienen lugar los tradicionales Liberal (PL) y Conservador (PC) y los nuevos PU, Cambio Radical (CR) y Verde (PV). Esta nueva situación había permitido reducir los niveles de polarización a los que la ciudadanía se había acostumbrado durante la era Uribe. En ese sentido, el único partido declarado en oposición es el Polo Democrático Alternativo (PDA), que cuenta hoy en día en su bancada con menos congresistas de los que logró que llegaran al legislativo, ya que durante 2012 sufrió la escisión de algunos de sus representantes debido a fraccionamientos internos.

Sin embargo, la arena política se tornó confusa porque el partido de gobierno, el PU, era a la vez el partido de las colectividades más descontentas con la agenda de gobierno. No había forma que la U de Uribe fuera al mismo tiempo la U de Santos. Salvo la izquierda, no era claro cuál era la oposición y cuáles eran los partidos progobiernistas. El sistema de partidos era un caos ideológico. Un sector del PV -plataforma para el principal contrincante de Santos en las pasadas elecciones, Antanas Mockus- se había aliado con Uribe para disputar las elecciones de Bogotá a la vez que ingresaba como uno de los miembros de la coalición de gobierno de Santos. ${ }^{1}$ El PL, que había permanecido en la oposición durante los gobiernos de Uribe, terminó convirtiéndose en un aliado incondicional de Santos. El PC y el PU, que habían apoyado a Santos, quedaron en medio de un fuego cruzado cuando el expresidente Uribe comenzó a mostrarse en desacuerdo con los cambios introducidos por Santos.

Las elecciones locales de octubre de 2011 fueron un ejemplo de esto. El caos tanto ideológico, como partidista y programático se puso en evidencia a la hora de formar coaliciones para las elecciones locales gracias a que así lo permitía la reforma política

1 Durante la campaña presidencial de 2010 las encuestas mostraban una tendencia aplastante en favor del candidato del Partido Verde, Antanas Mockus. La razón de semejante favorabilidad, que luego no se concretó en las urnas, radicaba en que el partido estaba compuesto por figuras que, para la opinión pública, se mostraban como honestas y competentes como Enrique Peñalosa, Lucho Garzón, hoy con un puesto en el gobierno nacional, y Sergio Fajardo, actualmente gobernador del departamento de Antioquia. 
aprobada ese mismo año. Para estos comicios tuvo lugar un gran número de alianzas entre diferentes partidos, candidatos y movimientos, las cuales no se reprodujeron con los mismos integrantes a lo largo del territorio, sino que variaron en cada región e incluso en los municipios de un mismo departamento (Batlle, 2012: 168). Con una lógica de competencia no siempre similar a la del nivel nacional, los espacios de poder local y regional son cada vez más valorados por los partidos y los políticos y los cambios que se producen en la competencia en estos niveles de gobierno tienen repercusiones claras sobre la dinámica y la agenda política nacional. Por un lado, se consolidaron algunas fuerzas partidistas nuevas en los diferentes niveles de competencia, como es el caso del PU -que cuenta con la Presidencia, varios cargos en el nivel subnacional y con una mayoría de escaños en ambas cámaras del Legislativo nacional- y otras tradicionales, como el PLC, que recuperó gran parte del terreno perdido en los últimos años. Por otro, parece consolidarse la opción de los movimientos ciudadanos, que varían de una elección a otra así como las candidaturas por firmas.

Estas elecciones, junto con el fin de la "amistad" de Santos y Uribe así como una nueva fractura de la izquierda, que, como se dijo anteriormente, terminó en la salida de algunos congresistas del partido y del actual alcalde de Bogotá, Gustavo Petro, cambiaron en gran medida el panorama nacional y agregaron nuevos elementos al análisis de las dinámicas propias del sistema de partidos colombiano. El sistema de partidos colombiano, que venía haciendo implosión desde hacía mucho tiempo (Gutiérrez, 2007), llegó a un punto crítico con la elección de Santos por la capacidad de Uribe de interpretar las preferencias políticas de amplios sectores de la población y por su incapacidad de convertir estas preferencias en decisiones institucionales.

En el marco de los cambios que se venían dando desde la llegada de Santos al poder y que se fueron concretando con más fuerza en las últimas elecciones subnacionales, el 5 de julio de 2012 Uribe aprovechó la desconfianza de las conversaciones con las FARC y el resentimiento de la clase política con Santos para renunciar al partido de la PU y lanzar un proyecto político de oposición, el Puro Centro Democrático. ${ }^{2}$ De una parte, estaba el PU a la cabeza de la coalición de partidos que respaldan al gobierno de Santos y aun cuando existían fuertes matices ideológicos entre sus componentes, la unidad estaba fundada en torno a un respaldo a la salida negociada al conflicto y a políticas progresistas en temas como el aborto, los derechos humanos, la igualdad de las parejas homosexuales, cuestiones ambientales, la legalización de la dosis personal de drogas, los derechos de las minorías, etc.

De otra parte, estaba como la principal fuerza opositora el CD, aún en proceso de constitución formal como partido. Esta fuerza estaba aglutinada alrededor de Uribe, los disidentes de la $\mathrm{U}$ y la mayor parte del partido Conservador. Al día de hoy, el CD planea lanzar una lista al Congreso encabezada por el expresidente Uribe así como su propio candidato presidencial. En este contexto, las últimas encuestas demuestran que

2 Ver reporte del evento en la Silla Vacía, Uribe oficializa su campaña para el 2014, 5 de julio de 2012. En: http:/ / www.lasillavacia.com/historia/uribe-oficializa-su-campana-para-el-2014-34506. 
la reelección de Santos, que parecía asegurada por la disponibilidad de recursos y la constante aparición mediática del gobierno, parece estar amenazada, no solo por esta polarización en torno a la figura del ex-presidente, sino por otras cuestiones que han minado sus niveles de aceptación popular, como se describirá más adelante.

\section{La izquierda conserva Bogotá: el primer año de gobierno de Gustavo Petro}

El fracaso de la gestión del alcalde Samuel Moreno - cofundador del PDA- en Bogotá ${ }^{3}$ y sus innumerables escándalos de corrupción, llevaron al sector de Gustavo Petro -candidato presidencial por ese mismo partido de izquierda en 2010- a declararse en oposición al alcalde e incluso a denunciar con vehemencia hechos de corrupción de su gobierno, lo que causó una ruptura con otros sectores y su salida del PDA. El de Moreno era el segundo mandato del PDA en Bogotá, después de la gestión de Luis Eduardo Garzón elegido en 2004. De esta manera, con una agenda de lucha contra la corrupción y superación de la segregación, así como una reputación ganada como senador y candidato presidencial por el PDA, Petro se hizo elegir como el tercer alcalde consecutivo de izquierda en la capital del país a través de su novissimo movimiento Progresistas. La llegada de un guerrillero desmovilizado al segundo cargo de elección popular más importante del país prometía un nuevo avance de la democracia colombiana.

Sin embargo, llevar a cabo su agenda de gobierno no le ha resultado fácil en la medida en que su incapacidad de gestión ha estado acentuada por su enfrentamiento con diferentes sectores como las élites políticas y económicas de Bogotá, por un lado, y sus antiguos copartidarios del PDA, por el otro. Además, muchas de las decisiones en las que ha fundado sus políticas han estado teñidas por la improvisación, ${ }^{4}$ cuestión que resulta acrecentada por la escasa experiencia política de parte de su gabinete y las continuas renuncias de sus funcionarios de confianza. ${ }^{5} \mathrm{Su}$ primer año al mando de la capital ha mostrado una brecha significativa entre su ambicioso programa de gobierno y su capacidad real de administrar una ciudad que, con sus más de siete millones de habitantes, no resiste los golpes de decisiones tomadas sin planeación ni rigor.

En el marco de esta situación, la mayoría de los medios de comunicación han tomado parte en contra del alcalde haciendo clara oposición y cuestionando sus decisiones y declaraciones; a lo cual el alcalde ha acostumbrado a la opinión pública a gestionar estos disensos desde su cuenta de Twitter. Asimismo, al haber llegado al Palacio de Liévano con una plataforma electoral nueva que alcanzó escasos ocho escaños en el Concejo Distrital -de los 45 que lo conforman- la administración ha tenido que enfrentarse a innumerables trabas impuestas por las mayorías, conformadas por el PU, el PDA, los

3 Ver reporte del evento en la Silla Vacía, Uribe oficializa su campaña para el 2014, 5 de julio de 2012. En: http:/ / www.lasillavacia.com/historia/uribe-oficializa-su-campana-para-el-2014-34506.

$4 \quad$ El más reciente caso de improvisación tuvo que ver con la suspensión del contrato de recolección de basuras a una serie de firmas privadas dejando la ciudad sin un servicio de recolección alterno.

5 Entre los que renunciaron durante el primer año de la administración se encuentran: Antonio Navarro Wolff, secretario de gobierno; Daniel García Peña, Director de relaciones internacionales; Eduardo Noguera, secretario general, así como varios gerentes del sistema de transporte Transmilenio, entre los más sonados. 
Conservadores, Cambio Radical, el Partido Verde y algunos sectores del liberalismo, minando a todas luces sus niveles de gobernabilidad.

De todas maneras, un año de gobierno es poco para poder hacer un balance real de la gestión de Petro, quien, pese a sus opositores, ha demostrado ser un hábil político y ha conseguido ser centro de atención de los medios tanto a nivel nacional como territorial; de hecho, algunos han intentado aprovechar estas circunstancias para promover una revocatoria de su mandato que, de llegar a las urnas, le dará a Petro una nueva oportunidad de reivindicar su plataforma ante los votantes. También se especula sobre una eventual aspiración presidencial de Petro, cuestión que en este contexto parece poco probable. Lo que sí queda claro es que, más allá de los nombres de los candidatos y las etiquetas que utilizan para competir, Bogotá sigue siendo el bastión más importante de la izquierda en Colombia y, seguramente, sus miembros harán lo posible por mantenerlo.

\section{Los otros...}

Entre los tradicionales, los grandes nuevos partidos como el PU y la izquierda, están los partidos conformados por figuras pertenecientes a la academia, a la tecnocracia o a los medios de comunicación que logran conseguir votos y mantenerse vigentes a través de un discurso antipolítico. Sin embargo, este tipo de colectividades, por su propia concepción, no dispone de una base de políticos profesionales que los mantengan vigentes en fechas distintas a las de elecciones. Eso sin mencionar las disputas que ocasionan los egos de sus principales figuras. El PV, la principal coalición de este tipo de figuras, al día de hoy solo existe a partir de las declaraciones esporádicas que realizan sus líderes y un puñado de congresistas y tiene muy poca presencia a lo largo del territorio.

Finalmente está toda una serie de partidos que se arman de manera coyuntural para soportar las aspiraciones de políticos profesionales a cargos intermedios como curules en el Congreso, alcaldía y gobernaciones de segundo nivel, concejos, etc. Estos partidos encontraron una oportunidad en el ambiente de la Constitución del 91 que planteaba una apertura a la participación de las minorías políticas. Lo que aprovecharon muchos miembros de la clase política para independizarse del lastre y la disciplina de los partidos tradicionales. La disponibilidad de recursos provenientes del narcotráfico, la corrupción, los juegos de azar y demás rentas criminales, así como el respaldo de organizaciones mafiosas y paramilitares, propició el florecimiento de estos partidos.

Convergencia Ciudadana, Apertura Liberal, ALAS, PIN, ADN y un sinnúmero de siglas son los nombres de estas colectividades que aparecen y desaparecen cada tanto, cuando sus integrantes son investigados y encarcelados por vínculos con actividades o grupos criminales. De todos modos, las grandes coaliciones políticas que gobiernan el Estado usan a estos partidos para obtener las mayorías necesarias en la mecánica de la democracia dado que sin mayorías es imposible tramitar la agenda legislativa para sacar adelante los planes de gobierno. 


\section{LA PRIMERA MITAD DE LA ADMINISTRACIÓN SANTOS: BALANCE Y PERSPECTIVAS}

La ausencia de una oposición fuerte, junto a la bienvenida que le dieron muchos sectores sociales a la agenda reformista de Santos se tradujeron en altos índices de popularidad. Sin embargo, el presidente decidió elevar las apuestas. A principios de 2012 existían crecientes rumores sobre la apertura de un proceso de paz con la guerrilla, lo cual tenía hondas repercusiones en el clima de la opinión pública y en el alineamiento de la población en torno a las colectividades políticas. Un proceso de paz con las FARC era una apuesta arriesgada porque existía el precedente del proceso del Caguán, liderado por Andrés Pastrana entre 1998 y 2002, lo que implica que independientemente de si el actual proceso de paz tiene éxito o no, el solo hecho de negociar con las FARC es en sí un factor de enorme desconfianza hacia el gobierno. ${ }^{6}$

\section{El deterioro de las relaciones con el Congreso y la pérdida de territorio nacional}

A los problemas de popularidad implícitos en la negociación se sumó otra falla en el gobierno de Santos. Por su falta de experiencia en el manejo de la política menuda -de hecho Santos nunca había participado en ninguna elección hasta la campaña presidencial-, por la influencia que alcanzó una tecnocracia cortada por la misma tijera en el manejo de su gobierno -casi todos graduados en la misma universidad y provenientes de círculos bogotanos-, por el desdén en el trato a la clase política, entre otras tantas razones, el gobierno comenzó a mostrar una pobre capacidad de transacción con sus bancadas en el legislativo. ${ }^{7}$

Un caso muy concreto ilustra esta incapacidad y fue el impasse entre Ejecutivo y Legislativo que se originó a partir de la aprobación en el Congreso de la reforma a la justicia propuesta por la Presidencia. El 11 de julio de 2011 fue nombrado como Ministro Juan Carlos Esguerra, ex-constituyente y ex-ministro, cuya misión principal era llevar a buen puerto la reforma a la justicia que venía promoviendo el presidente. Al comenzar la nueva legislatura se presentó la iniciativa para su discusión en el Congreso. Habiendo superado los ocho debates reglamentarios para una reforma de tipo constitucional, el proyecto de ley llegó a la comisión que conciliaría los textos resultantes de los debates de Cámara, por un lado, y Senado, por otro.

Como suele suceder a las nuevas normas que pasan por el congreso, los legisladores le agregan pequeños cambios que favorecen intereses personales, en este caso puntualmente

6 Entre 1998 y 2002 el presidente de entonces, Andrés Pastrana, despejó en favor de las FARC un área superior al tamaño de Suiza para adelantar diálogos de paz. Desde esta área, la guerrilla cometió toda serie de abusos y acciones criminales. Lo más grave fue que luego de casi cuatro años, el proceso no avanzó ni un centímetro. La popularidad del presidente Pastrana al final de su mandato ha sido la más baja en la historia reciente del país.

7 El llamado revolcón ministerial del gabinete presidencial que tuvo lugar durante 2012 resultó en el cambio de Ministros en las carteras de: Justicia, Interior, Minas y Energía, Hacienda y Crédito Público, Medioambiente, Defensa y Vivienda. Han sido estables las de Cancillería, Comunicaciones (TIC), Educación, Cultura, Agricultura. A pesar de estos cambios, la opinión pública reclamaba cambios de mayor impacto. Al respecto véase “¿Cuál revolcón ministerial?", en El Espectador, 31 de agosto de 2012. 
relacionados con el régimen de inhabilidades, pérdida de investidura y doble instancia en el juzgamiento de congresistas. Aun así, el ministro fue enfático en solicitar a los congresistas que aprobaran dicha reforma a pesar de no resolver todos los problemas que pretendía. Pero el 21 de junio de 2012, tan pronto como la prensa y algunas organizaciones de la sociedad civil comenzaron a denunciar la inconveniencia de dichos cambios, el presidente ordenó devolver la reforma al Congreso por estar plagada de vicios. Santos argumentó que el gobierno no conocía los cambios establecidos a última hora y que "se introdujeron cambios que en nada favorecen a la justicia y a la transparencia" a la vez que acusó a la comisión conciliadora de "desbordar sus competencias". ${ }^{8}$ Los congresistas, que son políticos curtidos, rápidamente le demostraron lo contrario y quedó claro que el gobierno sabía. ${ }^{9}$ Esto implicó archivar la discusión de una necesaria reforma a la justicia en Colombia, así como la salida del entonces Ministro.

Este revés del presidente no le salió tan bien como le habían salido hasta entonces sus principales jugadas políticas. Haber hundido la reforma le causó al mandatario no solo el inicio de una caída libre en sus índices de popularidad, sino el fin de su luna de miel con el Congreso: el legislativo, que es fundamental para sacar adelante la agenda de gobierno, desconfía ahora del presidente. ${ }^{10}$ Por algo, casi tres años después del inicio de su gobierno, su proyecto de modernización del país no ha podido ser avalado por el Congreso.

Asimismo, de manera casi inesperada por la mayoría de los analistas políticos, un incidente de política exterior minó aún más la popularidad de Santos, al conocerse el fallo del Tribunal de La Haya sobre el diferendo limítrofe que Colombia mantenía con Nicaragua y que tuvo como resultado la pérdida de más de 90.000 kilómetros cuadrados de mar territorial para los colombianos. Dicho diferendo, sustentado en el reclamo histórico por parte de Nicaragua -y particularmente los gobiernos sandinistas- por la soberanía del archipiélago de San Andrés, Providencia y Santa Catalina así como otros islotes colombianos cercanos a las costas nicaragüenses, respondía a una demanda presentada por Nicaragua ante la Corte Internacional de La Haya hacía poco más de una década.

Si bien la canciller de Santos -María Ángela Holguín- había sido de las mejor evaluadas del gabinete durante los primeros años del gobierno y su política exterior, tanto hacia los países vecinos como hacia el resto de América Latina, había sido caratulada como la más satisfactoria respecto de los últimos gobiernos; resulta irónico que haya sido un incidente de esta naturaleza el que golpeara con más fuerza sus niveles de aceptación. Aun cuando la estrategia de defensa del país ante La Haya se había gestado especialmente durante los gobiernos de Uribe y Pastrana, fue el de Santos el que recibió todo el peso de la decisión.

$8 \mathrm{Al}$ respecto véase "Santos objeta reforma de la justicia y la devuelve al Congreso" en El Tiempo, 22 de junio de 2012.

9 El senador liberal Camilo Sánchez, quien forma parte de la coalición de gobierno, sostuvo, en relación con la decisión del Ejecutivo, que "cada vez que tengan un problema no se pueden lavar las manos y echarle la culpa al Congreso". Al respecto véase “Cámara y Senado hundieron la reforma de la justicia”, El Tiempo, 28 de junio de 2012.

10 Aunque el porcentaje de iniciativas exitosas presentado por el Ejecutivo continúa siendo mucho mayor que el de las que se originan en el Congreso. 
La opinión pública le cobró sin piedad la falta de cálculo sobre las consecuencias tanto reales como simbólicas de esta pérdida de territorio así como la incapacidad y falta de claridad por parte del gobierno al momento de informar sobre el tema.

Teniendo en cuenta que Colombia ya había perdido, a comienzos del siglo pasado, otra gran porción de territorio, al tener que renunciar al istmo de Panamá, este fallo se constituyó en un duro golpe a la gestión de la Canciller, que tuvo repercusiones directas sobre la valoración de la administración por parte de la opinión pública. De igual forma, otras cuestiones como los onerosos gastos invertidos en la organización y celebración de la Cumbre de las Américas que se llevó a cabo en la ciudad de Cartagena en abril de 2012 y algunas declaraciones desacertadas de la Ministra, se sumaron a este clima de descontento con esa cartera y con el gobierno en general.

Gráfico 1: Imagen del Presidente Santos

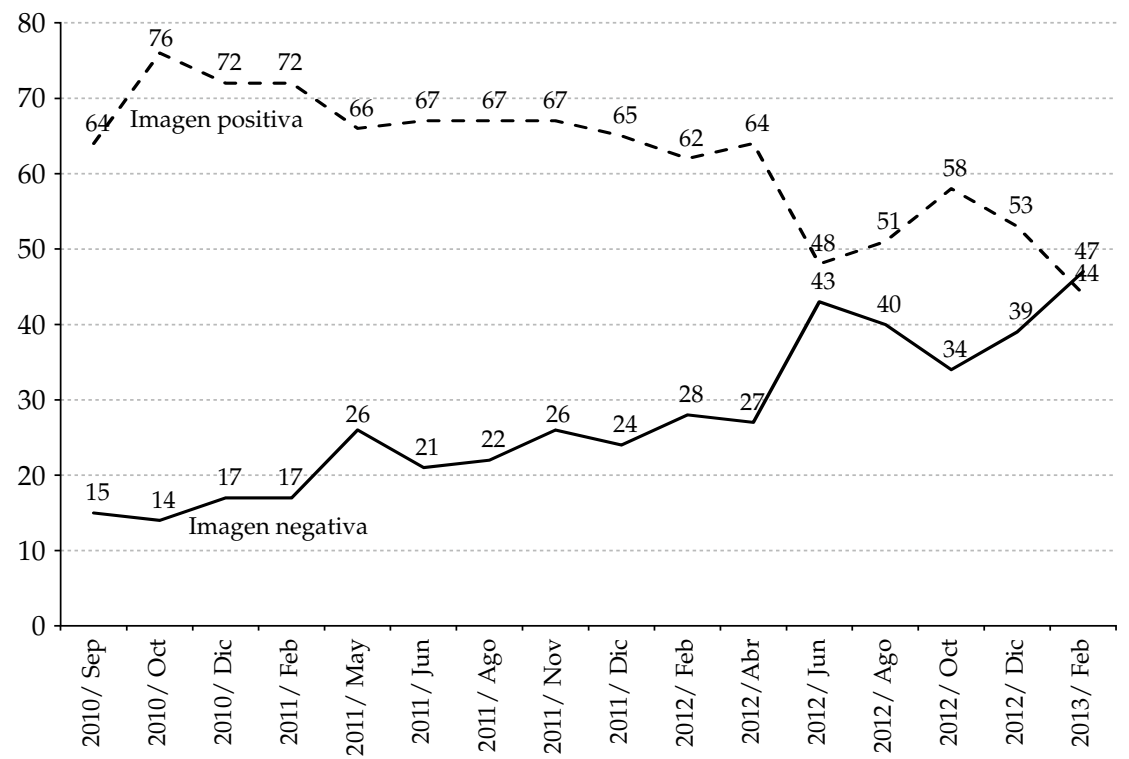

Fuente: La Silla Vacía con datos de la encuestadora Gallup.

En el marco de una popularidad en descenso y una relación cada vez menos aceitada con el Congreso, Santos ha comenzado a recorrer el país de manera mucho más decidida que en los primeros meses de su mandato y ha buscado poner el acento en otro tipo de políticas que han venido demostrando ser exitosas como las de reparación a víctimas del conflicto armado, la de restitución de tierras a aquellos que las perdieron como resultado también del conflicto y la construcción de 100.000 viviendas gratuitas a lo largo del país. $\mathrm{Al}$ centrarse en estos temas, que aquejan especialmente a poblaciones de la periferia así como a sectores de clase baja, el presidente busca hacer presencia y acercar su gobierno 
a las diferentes regiones y grupos socioeconómicos, probablemente intentando construir mayor capital político para su competencia por la reelección.

\section{¿Hacia el fin del conflicto?}

Bajo las actuales circunstancias las FARC son la organización armada irregular que plantea una mayor resistencia al Estado. La ortodoxia comunista imprime a la guerrilla una lógica muy distinta a la de las mafias y a los ejércitos paramilitares. Mientras estas organizaciones centran sus esfuerzos en la dominación de regiones y espacios muy específicos, la guerrilla encuentra en el dominio local en la periferia un paso intermedio para transformar la sociedad y apropiarse del estado central. No es de sorprender entonces las recurrentes alianzas de miembros del Estado y del establecimiento con mafias y paramilitares para contener a las FARC. Lo paradójico es que han sido los mismos recursos producidos por las mafias y los paramilitares los que han propiciado el crecimiento de la guerrilla. En las últimas tres décadas, las FARC han estado involucradas en el narcotráfico, pero no puede concluirse, como erróneamente lo afirman diversos medios, que operen como un típico cartel narcotraficante. Las relaciones de las FARC con las drogas deben analizarse desde la perspectiva del tipo de actividad productiva del narcotráfico que ocurre en sus zonas de dominación. Ha sido una relación que responde a la base colona y campesina que provee los soldados rasos de esta guerrilla.

Las FARC se encontraron con el narcotráfico en el momento en que los narcotraficantes de los carteles de Medellín y de Cali necesitaron crear una fuente de producción de cocaína distante de los centros urbanos del país. Por estar en medio de la selva, eran territorios ideales para montar grandes laboratorios clandestinos de producción de cocaína. La guerrilla recibía un pago por cuidar los laboratorios. En un momento dado, los narcotraficantes llevaron los cultivos ilícitos a la zona a pesar de que las FARC se mostraron reacias a permitir la siembra de coca. ${ }^{11}$ Pero finalmente la visión conservadora de la guerrilla de que 'las drogas corrompían a la revolución' tuvo que ceder ante los apremios de la población. En el largo plazo el desarrollo de los cultivos entre comunidades de colonos convertiría a Colombia en el principal productor mundial de hoja de coca. Las FARC se encargarían de poner orden en estas comunidades por el solo hecho de ser el Estado de facto.

A mediados de los noventa, la acumulación de fuerza y control territorial desde las zonas de cultivo de coca le permitieron a la guerrilla expandirse hacia las áreas más pobladas y desarrolladas del territorio. Los dos gobiernos de Uribe significaron su repliegue hacia los extramuros de la frontera agraria del país. Después de tantos esfuerzos, en

11 Gonzalo Rodríguez Gacha fue uno de los grandes promotores de la siembra de coca en las selvas y sabanas del suroriente del país. Creó sólidas bases clientelistas entre los campesinos e innovó con variedades de semillas más eficientes para los suelos locales (Cortes 1993). Otra versión sobre el desarrollo de los cultivos ilícitos la tiene Doble Cero, que atribuye al Cartel de Cali una alianza con las FARC como resultado del control por el Cartel de Medellín de los centros de abastecimiento de coca en Perú y Bolivia (Civico, 2009). La razón que tuvieron los narcotraficantes colombianos para traer los cultivos de coca al país era romper la dependencia de los centros provisión de base de coca en Perú y Bolivia. 
2012 estaban casi en la misma situación de sus inicios. No obstante, era una guerrilla en condiciones de subsistir. Los colonos coqueros necesitaban un Estado y las FARC eran los más adecuados para cumplir funciones básicas de provisión de justicia y orden.

El 27 de agosto de 2012 se acabaron las especulaciones: el presidente Santos le contó al país lo que ya muchos sabían. Luego de la ofensiva del Estado, las FARC ${ }^{12}$ finalmente habían aceptado sentarse a negociar. Indistintamente de los motivos para negociar, -el deterioro de su situación militar, el cansancio y envejecimiento de su jefatura, el riesgo de lumpenización y criminalización de la guerrilla, etc.- lo cierto es que la negociación involucra principalmente las expectativas de la élite de la guerrilla. 'Timochenko', 'Iván Márquez' y demás mandos así presuman de llevar una vida austera están lejos de representar los intereses genuinos de la población coquera que controlan en la frontera agraria del país. Defienden más bien el derecho a usar el poder que ejercen sobre esta población para aspirar a prerrogativas como el indulto o la participación política por decreto. De allí que no sea extraño que la dirigencia de las FARC, la que negocia con las elites nacionales, esté formada no por cuadros campesinos sino por antiguos militantes urbanos del Partido Comunista que la persecución del estado obligó a refugiarse en la selva pero que la guerra les dio la oportunidad de convertirse en élites, así fuera de la población más marginada del país.

Sin embargo, aun suponiendo que el proceso de paz llegue a buen término, es claro que el problema de sociedades basadas en la producción de hoja de coca no va a finalizar. No se avizora ningún tipo de producción legal que pueda ser regulada por las instituciones del estado capaz de absorber al centenar de miles de familias que viven de la siembra de hoja de coca. Los colonos coqueros van a ser los grandes marginados de la mesa de negociación sin importar que sobre sus hombros se hubiera sostenido el esfuerzo militar de las FARC.

Se trata del problema político de la imposición de instituciones de dominación alternas a las instituciones del estado. La pregunta es ¿qué tipo de instituciones de dominación surgirán si se desmovilizan las FARC o, si no se desmovilizan, podrán los mandos comunistas ortodoxos mantener las viejas instituciones de control local de la guerrilla ahora que la supervivencia depende de la mayor criminalización de sus frentes? En cualquiera de los dos escenarios la perspectiva es la profundización del proceso de difusión de los ejércitos de pequeños señores de la guerra relativamente desarticulados de proyectos políticos de alcance nacional.

12 Los resultados de la iniciativa militar de Uribe contra las FARC son palpables en numerosos indicadores de guerra que van de 2002 en adelante. El número de guerrilleros pasó de más de veinte mil a alrededor de diez mil. Las acciones militares y la presencia territorial de las FARC también se redujeron ostensiblemente, eso sin mencionar que finalmente el ejército colombiano pudo dar de baja a varios de sus principales líderes: “En el cuarto periodo, entre 2007 y 2010, en medio de la tendencia descendente que se impone en la confrontación armada, las fuerzas militares logran neutralizar varios de los mandos de las FARC, a lo cual el grupo guerrillero responde incrementando su accionar. No obstante que a partir de 2009 las FARC registran un repunte en sus acciones, la iniciativa militar contra las FARC alcanza su nivel más alto con 1.277 combates en promedio por año, frente a la muy disminuida iniciativa del grupo guerrillero expresada en la realización de 359 acciones. Los combates que las Fuerzas Militares libraron con las FARC superan la iniciativa del grupo guerrillero en el conjunto de los departamentos del país, excepto en Nariño". (Echandía, 2011). 
Aun así, para el Estado una eventual desmovilización de las FARC significaría un avance enorme en el propósito de imponer un monopolio de la fuerza a lo largo del territorio. Es el final de la única organización militar con capacidad y aspiración de poder nacional. Las demás guerrillas se encuentran diezmadas y las mafias y ejércitos de señores de la guerra son solo amenazas del orden local. El nuevo desafío es la reproducción sistemática de pequeñas organizaciones criminales a lo largo de numerosas regiones con capacidad de regular el orden local, lo que constituye la principal amenaza para la seguridad del país. Y si algún factor ha contribuido al florecimiento de mafias y señores de la guerra con capacidad de regulación social, ha sido la economía política de la periferia. En muchas zonas con nivel medio y bajo de modernización, la regulación del narcotráfico se ha extendido a la regulación del orden social en su conjunto. La situación se torna actualmente más dramática por las oportunidades que ofrece el auge de la minería informal e ilegal a organizaciones de coerción privada.

\section{COYUNTURA ECONÓMICA: ¿LOCOMOTORA MINERA?}

En los días siguientes a su posesión, en agosto de 2010, Santos y su entonces Ministro de Hacienda le anunciaron al país que uno de los motores del desarrollo iba a ser la "locomotora minera". Tenían razón, la minería había incrementado su participación en el PIB del país del 2,7\% a más del 7\% durante los últimos cinco años (cifras oficiales del Departamento Administrativo Nacional de Estadística -DANE-). El gobierno vendía la bonanza minera como un medio para evitar que Colombia fuera presa de la recesión mundial y para señalar el buen momento de las finanzas nacionales. Los críticos, por su parte, advertían inminentes síntomas de enfermedad holandesa como la dramática revaluación del peso colombiano y al crecimiento de las importaciones. La discusión macroeconómica, sin embargo, olvidaba ciertos efectos políticos de la conversión del país en una economía minera que se revelarían en el transcurso del 2012.

La explotación de productos como petróleo y carbón tiene como característica en su organización empresarial la necesidad de enormes inversiones en tecnología y logística para poder encontrar, extraer y transportar los recursos naturales a los mercados mundiales. Solo grandes compañías multinacionales disponen del capital para estas tareas, por lo que la distribución de los excedentes en el país y en las regiones depende principalmente de las regalías e impuestos que deje la explotación. Las rentas mineras son entonces el producto de transacciones políticas entre todo tipo de actores que no tienen mayor preocupación en la empresa capitalista en sí, sino en cómo acceder al poder político para participar de las ganancias de la minería.

Por si fuera poco, el efecto que tiene la explotación de recursos como el petróleo y el carbón en la política, el auge de nuevos productos minerales con características menos complejas en sus métodos de explotación ha agudizado el papel de la violencia en la economía política de las regiones colombianas.

El oro en particular se ha convertido en un tema crucial dentro de la evolución del conflicto colombiano. Al no tratarse de una mercancía que requiera enormes inversiones para su 
Gráfico 2: Exportaciones en millones de dólares FOB (octubre de 2012 vs octubre de 2011)

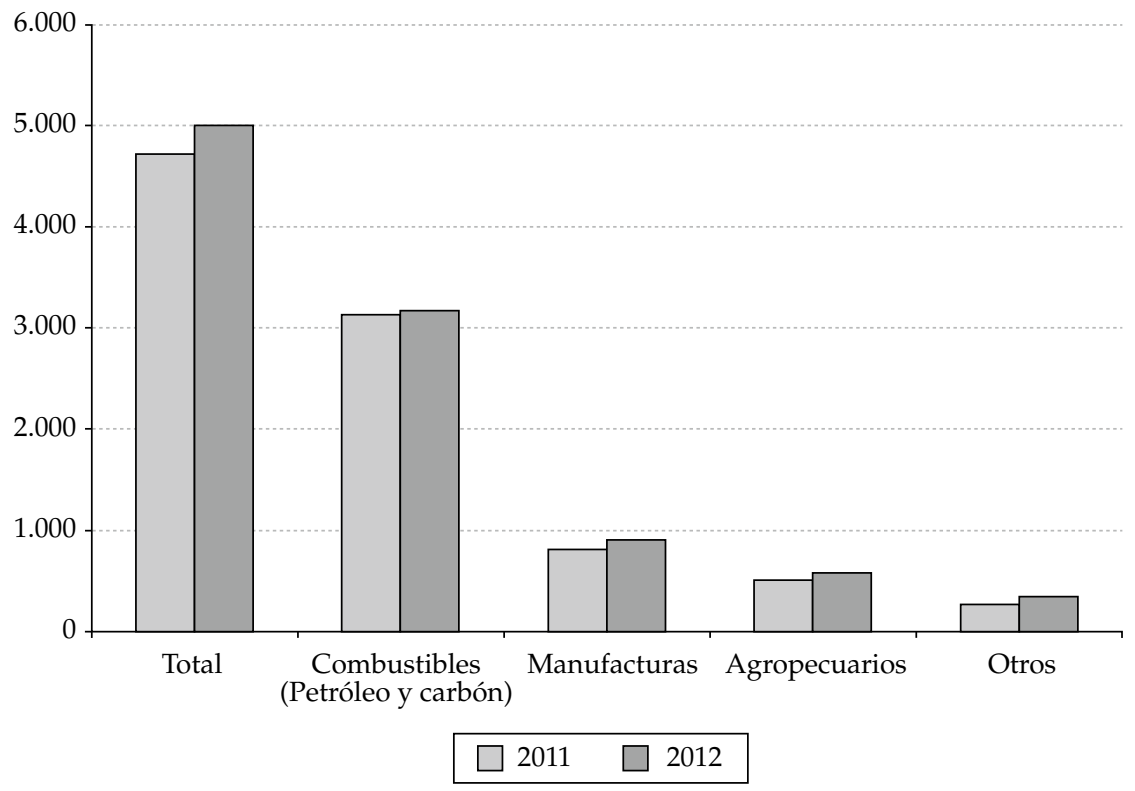

Fuente: DANE.

extracción y transporte, mineros independientes y empresas pequeñas han comenzado a competir con compañías multinacionales por el derecho a la explotación. Giraldo y Muñoz (2012) hallan que con el boom de los precios del oro en los mercados mundiales el país produce anualmente 3.000 millones de dólares de acuerdo con una estimación conservadora. Una parte de esta renta se queda en las manos del Estado y de compañías formalmente constituidas que explotan las minas respetando la normatividad ambiental y tributaria. La otra parte se queda en las manos de mineros artesanales, informales e ilegales y de los grupos armados irregulares que imponen su ley en los márgenes del Estado. Es una renta tan importante que al día de hoy no pueden comprenderse las guerras en regiones enteras como el sur de Bolívar y del Choco si no se considera el control de la explotación del oro.

Si la renta es enorme, el volumen de población involucrado lo es más porque mientras las empresas formales son intensivas en capital, las informales son intensivas en trabajo. De acuerdo con Giraldo y Muñoz (2012), las cifras más conservadoras advierten que 150.000 colombianos viven de la minería del oro. Ni más ni menos que una cifra similar a la de los campesinos cocaleros en tiempos de la bonanza coquera. Con el agravante de que la mayoría de esta población es regulada por los nuevos ejércitos paramilitares, mafias y guerrillas. En otras palabras, por razones de la tecnología de explotación el Estado queda del lado de grandes compañías que son contrarias a los intereses básicos de un amplio sector de la población, pues no crean empleo ni invierten las ganancias en la economía local. 
Otro hallazgo importante del estudio ha sido la política tan excluyente del gobierno contra los mineros artesanales, informales e ilegales. Giraldo y Muñoz (2012) citan al Ministro de Minas Mauricio Cárdenas: "A la minería ilegal hay que darle el mismo tratamiento que al narcotráfico. Es un fenómeno muy similar. ¿Qué pasa cuando la policía agarra un laboratorio? Lo destruye. La maquinaria incautada la pueden tener separada de esas actividades unos días o semanas, pero no pueden dejar a unos policías cuidándola".

Estas declaraciones al diario El Tiempo contrastan con el interés mostrado por Santos por poner el tema de la legalización de la droga en la agenda internacional. El propósito de Santos es mostrar que si alguna lección ha enseñado la guerra contra las drogas es que el problema no ha sido la actividad económica en sí, sino su regulación por organizaciones armadas distintas al Estado. Y si ha existido una regulación alterna por guerrillas, paramilitares y mafias es porque el Estado no puede regular la producción de drogas por ser mercancías ilegales.

Al criminalizar la minería lo que hace el gobierno es alimentar las condiciones para que todo tipo de ejércitos irregulares asuman el control del orden social en las zonas mineras del país. La criminalización de la minería del oro significa entregarles una base social a los grupos armados al margen de la ley equivalente en número a la población cocalera. Es casi como multiplicar por dos la población por fuera del control del Estado y multiplicar el riesgo de la violencia homicida ahora que los precios internacionales y la producción experimentan una bonanza inusitada. ${ }^{13}$

A principios de 2012, ante la evidencia de una nueva ola de violencia producida por la explotación aurífera, el gobierno ha lanzado una campaña contra la minería ilegal. Pero así ejércitos irregulares y narcotraficantes participan en la organización y financiación de la minería ilegal en Colombia, la carga del trabajo reposa en los centenares de miles de colonos y desarraigados que están dispuestos a irse a las zonas más recónditas de la geografía en busca de fortuna o simplemente en busca de una alternativa de vida. La bonanza del oro es solo la oportunidad de inclusión en el mercado que ofrece un commodity que disfruta de precios altos en el mercado internacional. El problema es que la inclusión en el mercado está asociada a la agudización de otro tipo de exclusión, la del Estado.

La criminalización del oro ha sido en la práctica la renuncia del Estado a incluir dentro de su campo de regulación a esta población. El potencial de riqueza aurífera es un hecho. Si no lo explota la población nativa y los colonos, lo explota alguna gran compañía que cuente con los medios tecnológicos y el capital para cumplir todas las demandas regulatorias de la ley. Este es de hecho el tipo de compañía que el Estado quiere involucrar. El resultado ha sido que la reciente persecución a la minería ilegal está asociada a una división política entre el Estado que defiende a los grandes capitalistas y unos neoparamilitares y unas neoguerrillas que defienden a los excluidos del Estado. Al

13 Idrobo, Mejía y Tribin (2012) en un análisis sobre la violencia en las zonas de explotación de oro encuentran que la tasa de homicidios mantiene una tendencia claramente superior a la de los municipios donde no hay explotación aurífera a pesar de que en 2006, antes del auge de la minería del oro, la tendencia era similar. 
tomar partido por las compañías que pueden cumplir con los requerimientos de capital, tecnología y cuidado ambiental en la explotación aurífera, el Estado está propiciando un fenómeno de deslegitimación que ya es palpable en las zonas auríferas del país en el que ven al gobierno como un aliado de las compañías multinacionales.

\section{CONCLUSIONES}

El año 2012 en Colombia abrió las puertas a un nuevo proceso de diálogo con la guerrilla de las FARC, aun cuando se esperaba que estas puertas permanecieran cerradas mucho tiempo más, como resultado, por un lado, del fracaso del intento de diálogo que tuvo lugar durante el gobierno del conservador Andrés Pastrana y, por el otro, de ocho años de ofensiva a la guerrilla en el marco de la política de seguridad democrática de Álvaro Uribe. Ante este escenario, en el que se reacomodaron las fuerzas políticas y se polarizó aún más el espectro ideológico en negociación versus guerra, surgen muchos interrogantes.

Entre estos, ¿cuáles son los verdaderos intereses de las FARC en este proceso? ¿Existe una agenda oculta? ¿Se puede negociar con las FARC como un todo o la cúpula, reunida en La Habana, ya no representa ni tiene poder sobre los guerrilleros rasos o mandos medios? ¿Qué reformas institucionales habría que llevar a cabo para abrir la posibilidad de inserción y representación democrática de las FARC en elecciones? Y aún más ¿está la sociedad colombiana preparada para que esto suceda?

En 2014 se realizarán unas nuevas elecciones presidenciales y legislativas en Colombia. Aunque Santos aún no se ha manifestado al respecto, el intento de reelección parece el escenario más probable. Sin embargo, el resultado o los avances de los diálogos con la guerrilla de las FARC tendrán una incidencia directa sobre esta decisión así como sobre los cálculos de los candidatos al Congreso a la hora de estructurar las listas electorales y, probablemente, de los resultados y la conformación de un nuevo gobierno y un nuevo Congreso. En ese sentido, la mesa de unidad nacional podría fracturarse y, en ese caso, que la totalidad de partidos que la integran no apoyen las intenciones reeleccionistas de Santos.

Es probable que la competencia presente mayores niveles de fragmentación y que las alianzas sean menos inclusivas y amplias de lo que se había pensado. Sin embargo, habría que tener en cuenta que para las próximas elecciones al Congreso el umbral se elevará al 3\%, situación que, sin duda tendrá efecto sobre la llegada de partidos y sectores minoritarios al legislativo, lo que puede dar lugar a un escenario de pos-conflicto en el que dichos sectores queden sin representación, redundando en una paz sin minorías. Si llega a concretarse la aspiración de Uribe al Senado, como parece que sucederá, las elecciones legislativas de 2014 se tornarán más interesantes que sus antecesoras. Una aspiración del ex-mandatario podría llevar a los demás partidos a echar mano de sus mejores figuras para poder hacer frente a una lista uribista encabezada por Uribe.

Por otra parte, la minería y la explotación de recursos naturales no renovables se constituyen en este momento en una de las actividades económicas que mayores réditos le han dado a la economía, redundando en que Colombia se ubique como uno de los países 
latinoamericanos que más ha crecido en los últimos años y esto de manera sostenida. Sin embargo, aspectos ambientales así como la normativa del nuevo sistema de distribución de regalías plantean interrogantes respecto del desarrollo de estas actividades en el largo plazo. Del manejo que en los próximos años se le dé a la minería ilegal y, en general, a la locomotora minera depende que esta fuente de riqueza no se convierta en una nueva fuente de conflictividad como ya parece ser el caso de algunos departamentos del país -como Santander, Tolima y Antioquia- que empiezan a polarizar sus fuerzas políticas en torno a este debate.

\section{REFERENCIAS}

Batlle, Margarita. 2012. "Selección de candidatos en las elecciones locales y regionales de colombianas de 2011: Los casos de Huila y Santander". Reflexión política 27: 154-171.

Civico, Aldo. 2009. No divulgar hasta que los implicados estén muertos. Las guerras de "Doblecero". Bogotá: Intermedio editores Ltda.

Cortés, Fernando. 1993. Rodríguez Gacha. El mexicano. Bogotá: Intermedio Editores.

Echandía, Camilo. 2011. Situación actual de las FARC: Un análisis de los cambios en las estrategias y la territorialidad (1990-2011). Fundación Ideas para la Paz. Septiembre de 2011.

Giraldo, Jorge y Muñoz, Juan Carlos. 2012. Informalidad e ilegalidad en la explotación del oro y la madera en Antioquia. Medellín: EAFIT. Proantioquia.

Gutiérrez, Francisco. 2007. ¿Lo Que el Viento Se Llevó?: Los Partidos Políticos y la Democracia en Colombia, 1958-2002. Bogotá: Editorial Norma.

Idrobo, N., Mejía, D. and Tribin A. 2012. Illegal gold mining and violence in Colombia. Bogotá: Mimeo, CEDEUniversidad de los Andes.

Wills-Otero, Laura; Benito, Christian Iván. "De Uribe a Santos: cambios y continuidades de la política colombiana en 2011". Revista de ciencia política 32 (1). Disponible en <http:/ / www.scielo.cl/scielo. php?script=sci_arttext\&pid=S0718-090X2012000100005\&lng=es\&nrm=iso $>$. accedido en 14 abr. 2013. doi: 10.4067/S0718-090X2012000100005.

Margarita Batlle es Doctora en Ciencia Política por la Universidad de Salamanca. Coordinadora del Observatorio de Políticas, Ejecución y Resultados de la Administración Pública de la Facultad de Finanzas, Gobierno y Relaciones Internacionales de la Universidad Externado de Colombia donde también es profesora e investigadora. Entre sus publicaciones más recientes se encuentra el libro Política y territorio. Análisis de las elecciones subnacionales en Colombia, 2011, compilado junto a Laura Wills Otero. E-mail: margarita.batlle@uexternado.edu.co

Gustavo Duncan es Candidato a Doctor en Ciencia Política por la Universidad de Northwestern. Profesor de la Universidad de los Andes, Bogotá, y profesor invitado de la Universidad EAFIT, Medellín. Se especializa en temas de mafias, narcotráfico, violencia privada y sus efectos en la construcción de estado. Es autor del libro Los señores de la guerra, publicado por la editorial Planeta y de artículos como "Del campo a la ciudad en Colombia. La infiltración urbana de los señores de la guerra", publicado por el CEDE de la Universidad de los Andes.

E-mail: GustavoDuncan2009@u.northwestern.edu 